\title{
MODELO DE PREVISÃO DE DEMANDA DE FERROLIGAS UTILIZANDO REDES NEURAIS
}

\author{
Wanessa Pereira dos Reis 1,2 \\ Jose Adilson de Castro ${ }^{3}$ \\ Luiz Antônio Ferrarez de Castro ${ }^{2}$ \\ Alexandre José Ramos Valentim ${ }^{2}$ \\ Fausto Kunioshi ${ }^{4}$
}

\section{Resumo}

Atualmente a previsão de demanda se tornou um desafio para os gestores de estoque devido à necessidade em equilibrar o serviço da cadeia de suprimentos através do gerenciamento da disponibilidade do material e investimento em estoque. Este estudo propõe um método alternativo para a previsão de demanda de ferroligas utilizada na produção de aços planos da Companhia Siderúrgica Nacional, através de um código computacional baseado em Redes Neurais Artificiais (RNA). A metodologia consiste em destacar os principais fatores que modelam as redes neurais como: seleção das variáveis, quantidade das variáveis, arquitetura da rede, treinamento e previsão de saída. O modelo apresentado foi desenvolvido a partir da arquitetura Multi Layer Perceptron (MLP), utilizando um conjunto de dados tais como: consumo específico, lead time, produção mensal e anual da aciaria, estoque de segurança, no período de 2014 a 2016 . Os resultados obtidos com a utilização das RNAs foram comparados com os valores medidos no período em questão e também com um modelo previamente desenvolvido baseado em regressão multilinear. Os resultados encontrados através das RNAs apresentaram um grau elevado de exatidão comparado com o método de regressão multilinear.

Palavras-chave: Previsão de demanda; Ferroligas; Redes neurais artificiais.

\section{FERROALLOY DEMAND FORECASTING MODEL USING NEURAL NETWORKS}

\begin{abstract}
Nowadays, the demand forecasting has become a challenge to stock managers due to the need to balance the service from the supply chain through the administration of the availability of the materials and investment in stock. This study suggests an alternative method to the demand forecasting of the ferroalloy used in the production of flat steel in Companhia Siderúrgica Nacional (CSN) through a computer code based on Artificial Neural Networks (ANN). The methodology consists in implementing the main elements that model the neural networks, such as: selection of variables, number of variables, network architecture, training and outflow forecasting. The model was developed using the Multi-Layer Perceptron (MLP) concept, with a data set such as: specific intake, lead time, monthly and annual production of steel mills, safety stock, from 2014 to 2016. The obtained results with the use of the ANNs were compared to the values measured during the period above and also to a previously developed model based on multiple linear regression. The results obtained through the ANNs showed a higher of predictability compared to the method of multiple linear regression.
\end{abstract}

Keywords: Demand forecasting; Ferroalloys; Artificial neural networks.

\footnotetext{
'Universidade Federal Fluminense - UFF, Volta Redonda, RJ, Brasil. E-mail: wanessa.reis@csn.com.br

2Área de Planejamento de Materiais, Companhia Siderúrgica Nacional, Volta Redonda, RJ, Brasil.

${ }^{3}$ Programa de Pós-graduação em Engenharia Metalúrgica, Escola de Engenharia Industrial Metalúrgica de Volta Redonda, Universidade Federal Fluminense - UFF, Volta Redonda, RJ, Brasil.

${ }^{4}$ Área de Administração de Materiais, Companhia Siderúrgica Nacional, Volta Redonda, RJ, Brasil.
}

2176-1523 (C) 2019 Associação Brasileira de Metalurgia, Materiais e Mineração. Publicado pela ABM. Este é um artigo de acesso aberto distribuído sob os termos da licença Creative Commons CC BY-NC-ND (Attribution-NonCommercial-NoDerivs) - https:// creativecommons.org/licenses/by-nc-nd/4.0\%. 


\section{INTRODUÇÃO}

De acordo com o cenário econômico mundial, no qual as empresas estão inseridas, as mesmas buscam cada vez mais melhorias para garantir seu espaço no mercado. Onde os clientes estão cada vez mais exigentes e as empresas precisam atender as necessidades dos mesmos, e ao mesmo tempo reduzir custos visando manterem-se competitivas, otimizando seus processos.

Para aperfeiçoar seus processos, a previsão da demanda é um grande desafio para os planejadores devido às empresas visarem o equilíbrio entre $o$ investimento em estoque e o pleno atendimento de matérias primas junto aos processos produtivos com quantidade e prazos adequados. Tal tarefa se torna essencial para os processos de tomada de decisão e planejamento.

A eficácia desta administração faz a diferença com a concorrência, melhorando a qualidade, reduzindo os tempos, diminuindo os custos, oferecendo assim, uma vantagem competitiva para a própria empresa.

Esta operação determina o balanceamento criterioso entre o custo da falta e o custo do excesso de estoque, possibilitando uma visão do impacto no nível de serviço.

No contexto do abastecimento de matérias primas para uma usina siderúrgica a gestão de estoques ocupa um papel de destaque devido ao baixo tempo de reposição, elevado giro de estoque e elevado custo de aquisição, pois a compra dos mesmos na sua maioria está atrelada a commodities.

Segundo Ballou [I], existem várias técnicas e modelos de previsão de demanda, tanto baseado em métodos estatísticos quanto métodos de otimização. Assim, as redes neurais artificiais (RNA) surgem como uma alternativa para a previsão de demanda.

Como uma das principais metas do planejamento é diminuir o impacto das incertezas relacionadas ao futuro da empresa, o estudo de redes neurais artificiais vem sendo objeto de várias pesquisas e contribuindo como uma valiosa ferramenta para a previsão de demanda em vários segmentos.

As redes neurais, entretanto, possuem a vantagem de se utilizar do histórico e de dados disponíveis no processo e se adaptam de forma adequada a comportamentos não lineares das respostas. Há um grande destaque para as redes neurais denominadas Multi Layer Perceptrons (MLP) devido à sua facilidade de implementação e boa capacidade de previsão.

Atualmente o valor de consumo de ferroligas na Companhia Siderúrgica Nacional (CSN) gira em torno de $\mathrm{R} \$ 200$ milhões por ano, com um valor aproximado de estoque em R 16 milhões por mês. Com isso, o propósito deste trabalho visa analisar se o método baseado em redes neurais artificiais supera em eficiência, os métodos tradicionais baseados em regressões utilizando métodos estatísticos, possibilitando ganhos na qualidade de previsão, melhora no nível de serviço prestado aos clientes internos e maior ganho no valor imobilizado da empresa, otimizando seus estoques.

\section{MATERIAIS E MÉTODOS}

A metodologia para este trabalho consiste no desenvolvimento de um modelo de previsão de demanda de ferroligas por meio de redes neurais artificiais, onde os principais fatores que devem modelar a rede neural, segundo Setyawati et al. [2] são: seleção das variáveis de entrada, quantidade de variáveis, arquitetura da rede, treinamento e previsão da saída.

É destacada por Fish e Blodgett [3], a entrada das variáveis, porém a preparação dos dados é de suma importância para o desempenho da rede neural. Um papel importante na precisão é o número de entradas, pois conforme Setyawati et al. [2], quanto mais treinada a rede, maior sua precisão. Onde o método da minimização do erro conduz o algoritmo a convergir para mínimos locais [4]. Com esse propósito, para que os resultados se tornem mais confiáveis, foi realizado uma série de seções independentes de treinamento, tornando resultado aquele que apresentar menor erro de predição.

O modelo baseado em redes neurais artificiais foi desenvolvido baseado no algoritmo Multi Layer Perceptrons (MLP) implementado em linguagem FORTRAN partindo de um código previamente desenvolvido no Programa de Pós-Graduação em Engenharia Metalúrgica da Universidade Federal Fluminense e adaptado para esta aplicação.

\section{I Formulação Matemática da Rede}

Os pesos sinápticos $\boldsymbol{w}_{j i}$ nas redes neurais devem ser multiplicados pelos sinais de estímulo $x_{j}$ e/ou sinais oriundos dos neurônios das camadas internas $\boldsymbol{y}_{i}$ seguida de combinação linear (Equação I), sendo toda a informação desse neurônio repassada ao próximo através de uma função de ativação (Equação 2). $O$ neurônio genérico, $j$ pode ser descrito matematicamente pelas Equações I e 2 .

$$
\begin{aligned}
& u_{j}=\sum_{i=1}^{m} w_{j i}\left(y_{i} \vee x_{j}\right) \\
& y_{j}=\phi\left(u_{j}\right)
\end{aligned}
$$

As funções de ativação é o da tangente hiperbólica (Equação 3), para os neurônios de camadas ocultas e função sigmóide (Equação 4), para os neurônios da camada de entrada e saída. A cada sinal de entrada submetido à rede neural é apresentada uma resposta desejada. $O$ sinal de erro (Equação 5) é gerado após a realização dos cálculos comparando o sinal de saída da rede com a resposta desejada.

$$
\begin{aligned}
& \phi\left(u_{j}\right)=\tanh \left(u_{j}\right) \\
& \phi\left(u_{k}\right)=\frac{1}{1+\exp \left(-a u_{k}\right)} \\
& e_{k}=d_{k}-\phi\left(v_{k}\right)
\end{aligned}
$$


A retropropagação pela rede neural do sinal de erro altera os valores dos pesos sinápticos através da regra delta generalizada (Equação 6). A aprendizagem da rede neural ocorre quando o sinal do erro médio quadrático dos neurônios de saída (Equação 7) é minimizado a um valor pré-definido ou anulado.

$$
\begin{aligned}
& \Delta w_{j i}(n)=\alpha^{\prime} \cdot \Delta w_{j i}(n-1)+\eta \cdot \delta_{j} \cdot y_{i} \\
& \xi=\frac{1}{2} \sum_{k=0}^{m} e_{k}^{2}
\end{aligned}
$$

Conforme anteriormente, a rede neural utilizou software baseado no algoritmo Perceptron de Múltiplas Camadas desenvolvida por Castro et al. [5], com a rede neural contendo duas camadas ocultas.

Para regressão estatística, a análise dos resultados obtidos são basicamente quantitativos. Atualmente este modelo é utilizado para projetar redução de custos, nível de desempenho, melhoria na qualidade de atendimento. No caso deste trabalho, a regressão múltipla é similar à regressão simples, mas utilizando de múltiplas variáveis ao mesmo tempo.

Assim defini-se o modelo de regressão linear múltipla dado pela equação (Equação 8), onde $Y$ representa a variável resposta, $x_{1} \mathbf{e} x_{2}$ representam as variáveis independentes $\mathbf{e} \varepsilon$ representa o erro aleatório experimental. Modelo esse de regressão linear múltipla com duas variáveis independentes $\left(\begin{array}{lll}x_{1} & e & x_{2}\end{array}\right)$.Em que o termo linear é utilizado devido a equação (Equação 8) ser uma função linear de parâmetros desconhecidos $\beta_{0}, \beta_{1}$ e $\beta_{2}$ denominados coeficientes da regressão.

$$
Y=\beta_{0}+\beta_{1} x_{1}+\beta_{2} x_{2}+\varepsilon
$$

A partir da definição da equação que melhor representa a relaçao das variáveis pode-se obter a concepção do modelo estatístico de regressão (MER). Atualmente o método estatístico utilizado na área de planejamento da CSN considera como variáveis importantes para o cálculo de demanda de ferroligas o Plano Anual de Vendas e Produção (PVP), o Plano Mensal de Produção (PMP), consumo específico, previsão de consumo, lead time, estoque de segurança, estoque inicial no mês de cada matéria prima, histórico de consumo (período de 6 e 3 meses) e os parâmetros de reposição.

\subsection{Desenvolvimento do Cálculo}

A escolha das variáveis de entrada é um ponto importante para que a rede consiga atingir o objetivo proposto.

O modelo proposto de previsão de demanda visa ser aplicado a todos os ferros ligas, alumínios e carburantes utilizados na produção do aço bruto da aciaria da CSN, porém este trabalho será testado em apenas três materiais selecionados de maior impacto quanto ao valor de estoque e quanto a incerteza de demanda, sendo eles: Ferro Manganês Alto Carbono (FeMnAC), Alumínio Gotão (Al Gotão) e Ferro Nióbio (FeNb).
Vale ressaltar que as matérias primas FeMnAC e Al Gotão estão presentes na composição química de praticamente todos os graus produzidos na aciaria de planos da CSN, e o FeNb contido apenas nos graus $X X X 3$ e sua principal aplicação é em produtos microligados (aço contendo pequenas adições de Ferro Nióbio e Ferro Titânio) e em aços inoxidáveis.

As variáveis de entrada foram selecionadas a partir das informações que o planejamento utiliza atualmente para calcular o abastecimento das matérias primas.

- Plano Anual de Vendas e Produção (PVP) - variável que informa a produção prevista mês a mês baseada no orçamento da empresa e serve para cálculo de projeções futuras $(\mathrm{xI})$, unidade: toneladas;

- Plano Mensal de Produção (PMP) - variável que apresenta a produção a ser realizada no mês considerando as correções do PVP (x2), unidade: toneladas;

- Consumo específico - variável que define o consumo específico de cada matéria prima de acordo com a carteira de vendas e orçamento $(x 3)$, unidade: $\mathrm{kg} /$ tonelada de aço produzida;

- Previsão de consumo - variável calculada a partir da carteira de vendas/número de corridas e consumo específico de cada matéria prima ( $\mathrm{x} 4)$, unidade: toneladas;

- Lead time - tempo de reposição das matérias primas (produção/transporte) (x5), unidade: dias;

- Estoque de segurança - variável importante que define o volume de estoque mínimo operacional de cada material sem colocar a produção em risco $(\times 6)$, unidade: toneladas;

- Estoque inicial do mês - volume de estoque inicial de cada matéria prima no mês proposto para o cálculo da demanda $(x 7)$, unidade: toneladas.

Os modelos apresentados foram testados utilizando o mesmo conjunto de dados no período de janeiro/20I4 a dezembro/2016. No modelo de regressão a variável a ser prevista apresenta correlação com uma ou mais variáveis independentes.

Os dados são separados em conjuntos para se desenvolver o treinamento e validação da rede. $O$ conjunto de treinamento é usado durante o desenvolvimento da rede neural artificial e o conjunto de validação no momento de avaliação da habilidade de previsão do modelo treinado.

Durante o treinamento o vetor de pesos é ajustado, buscando diminuir a diferença entre as saídas estimadas e as desejadas até atingir o nível de precisão desejável [6].

Após atingir este ponto, a rede deverá ser testada aplicando o conjunto dos dados de validação. 
Para este trabalho foram utilizados $70 \%$ dos dados para treinamento e $30 \%$ dos dados para validação da rede neural artificial.

Pode se descrever que o modelo proposto da RNA treinada com o algoritmo back propagation é composta por quatro camadas: camada de entrada, duas camadas ocultas e camada de saída.

A camada de entrada ou neurônio de entrada é composto por sete variáveis da série de dados históricos no período de janeiro/20I5 a dezembro/2016. Camada oculta com duas camadas, onde uma possui seis neurônios e a segunda com três neurônios. A camada de saída é composta por um neurônio ( $y$-variável resposta).

Importante comentar que o método estatístico atualmente utilizado pela equipe de planejamento da CSN foi aplicado a partir do ano de $20 \mathrm{II}$ com um ganho significativo de $R \$ 2,5$ milhões em redução dos estoques de ferroligas. Com a utilização sistemática da nova metodologia adotada baseada no modelo de RNA, espera-se obter ganhos adicionais devido a um maior controle e previsibilidade da compra das matérias primas.

\section{RESULTADOS E DISCUSSÃO}

Considerando que hoje a CSN apresenta um giro de estoque de 13 vezes ao ano, considerado excelente no ramo siderúrgico, espera-se que a partir desse estudo com a criação de um modelo de previsão de demanda de ferroligas utilizando rede neural MLP possa atingir um nível mais elevado de precisão, trazendo outras vantagens como em relação à tomada de decisões estratégicas da empresa, redução do valor imobilizado do estoque, garantindo também melhor qualidade no atendimento aos clientes internos.

O estudo da rede neural artificial tem alta relevância para os pesquisadores de inteligência artificial, sendo objeto de crescentes pesquisas e servindo como previsão de demandas e espera-se uma maior adaptabilidade quando comparadas a técnicas estatísticas de regressão linear.

Os resultados deste trabalho mostram que o modelo baseado na RNA é um método alternativo viável comparado aos modelos tradicionais de regressão linear, devido a versatilidade da rede neural, onde ocorrendo variações nos cenários, a rede poderá ser treinada novamente para que os pesos sinápticos sejam novamente ajustados. Uma outra vantagem importante é que a rede pode ser ajustada para busca de mínimos e condições ótimas locais e não necessariamente utilizando todos os dados históricos para a busca das condições ótimas.

Foram criados dois conjuntos de dados para cada uma das matérias primas em questão: um conjunto para treinamento com dados históricos mensais de 2 anos de operação e planejamento da empresa. Foram selecionadas 192 amostras de forma aleatória para o treinamento; e outro conjunto para validação com 58 amostras restantes, em épocas de treinamentos distintos. $O$ treinamento da rede foi realizado por matéria prima utilizando-se os parâmetros conforme apresentados na Tabela I.

As medidas de dispersão da RNA encontradas no momento de validação da rede seguem na tabela (Tabela 2), onde são informados os resultados obtidos por erro médio percentual.

Como pode se observar os resultados encontrados pelo método RNA são bem mais próximos daqueles realizados nos períodos dos dados utilizados, onde os erros se tornam quase nulos como mostra as figuras

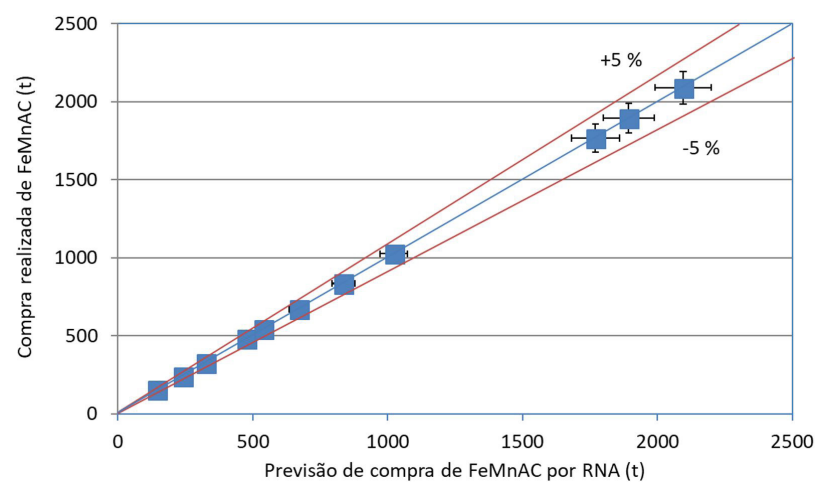

Figura I. Comparativo de previsão de compra calculado pela RNA e realizada no período de aplicação do modelo proposto com intervalo de confiança de $95 \%$ para a liga FeMnAC. Fonte: Autores.

Tabela I. Parâmetros do treinamento da RNA para cada matéria prima

\begin{tabular}{lccc}
\hline & FeMnAC & Al Gotão & FeNb \\
\hline Taxa de Aprendizagem & 0,01 & 0,01 & 0,01 \\
Constante de momento & 0,8 & 0,8 & 0,8 \\
Épocas de treinamento & 2400000 & 2400000 & 2400000 \\
\hline
\end{tabular}

Fonte: Autores.

Tabela 2. Erro médio percentual da RNA aceito para previsão de necessidade de compra para cada matéria prima

\begin{tabular}{ccccc}
\hline & & FeMnAC & Al Gotão & FeNb \\
\hline RNA & Erro médio & $0,94 \%$ & $0,11 \%$ & $0,50 \%$ \\
\hline
\end{tabular}

Fonte: Autores. 
(Figuras I, 2 e 3). Conforme observado, os valores previstos pela rede são bem próximos e apresentam uma consistência histórica com os valores realizados. Pode-se, portanto, concluir que a previsibilidade da

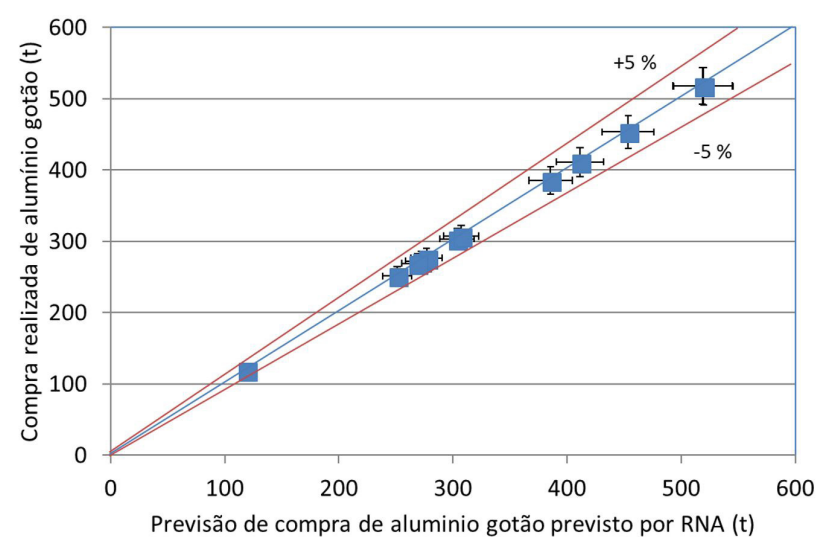

Figura 2. Previsão de compras em comparação à realizada durante o período de utilização do modelo proposto para alumínio Gotão (intervalo de confiança 95\%). Fonte: Autores.

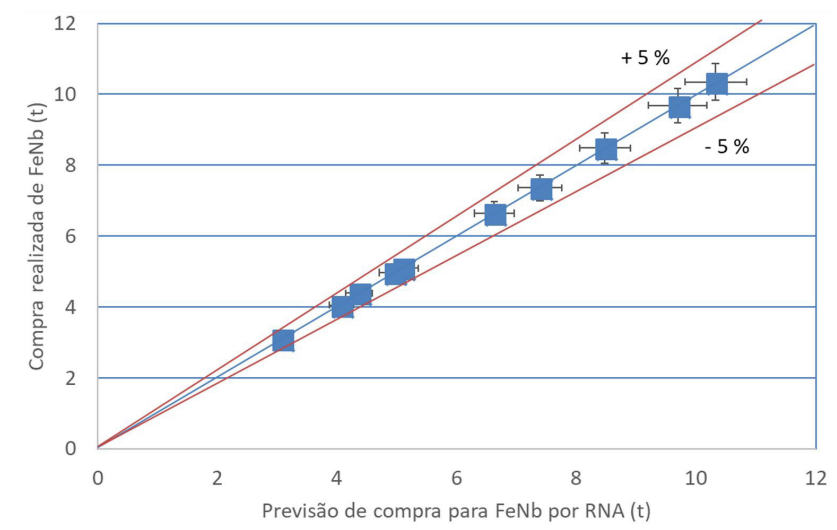

Figura 3. Comparativo de previsão de compra e respectiva realização para a variável resposta do modelo para FeNb (intervalo de confiança 95\%). Fonte: Autores.

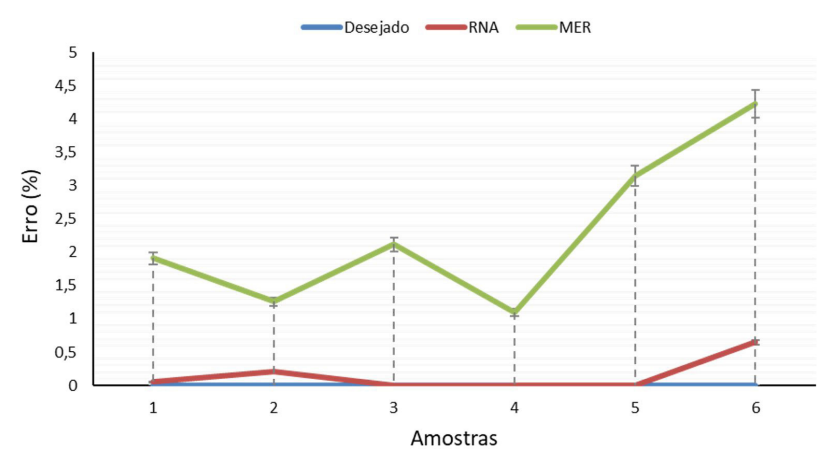

Figura 4. Comparativo do \% de erros RNA x MER para amostras aleatórias de previsão de FeNb. Fonte: Autores. rede é excelente, no caso especifico com intervalos de confiança acima de $95 \%$. O que pode ser considerada de excelente qualidade.

$\mathrm{Na}$ utilização do MER podemos destacar que os percentuais de erros nas previsões de compra de $\mathrm{FeNb}$ ficaram acima daqueles previstos pelo método RNA como apresentado na figura (Figura 4).

O percentual de erro quanto mais próximo ao zero maior será a assertividade de previsão da demanda de matéria prima. Similar comportamento foi observado para previsões de outras matérias primas. Pode-se observar, portanto que de forma geral, a rede apresenta uma previsão bem mais próximas daquelas realizadas, o que permitiria uma assertividade e, portanto, se trabalhar com cenários onde os custos de estoques seriam minimizados.

\section{I Cenários Propostos}

Foram levantados três cenários referentes a situações pertinentes a realidade da empresa quanto ao abastecimento de matérias primas para produção de aço na aciaria.

- Cenário I: FeMnAC com produção atual do ano de 2017, consumo específico médio e manutenção do estoque de segurança considerando abastecimento somente com matéria prima importada (lead time 90 dias);

- Cenário 2: Al Gotão com produção mensal na sua capacidade máxima, consumo específico médio e manutenção do estoque de segurança com cobertura de 10 dias;

- Cenário 3: FeNb considerando produção atual do ano de 2017, consumo específico médio e manutenção do estoque de segurança no mínimo operacional.

Para os cenários propostos, utilizou-se as duas ferramentas disponibilizadas neste estudo para se analisar a viabilidade de tais cenários.

Com aplicação da RNA e MER nos cenários propostos chegaram-se as seguintes previsões de demanda conforme tabela (Tabela 3). Vale ressaltar que os dados históricos utilizados para os dois métodos foram os mesmos visando se obter uma comparação direta entre os valores de predição (necessidade de compra de matérias primas).

Observa se que os cenários propostos são passivos de serem praticados na empresa.

Ressaltando que de uma forma geral o ajuste do MER é considerável bom também sendo da mesma ordem do modelo RNA, exceto para valores mais extremos, pois a maioria dos dados a serem previstos possuem menor variabilidade. 
Tabela 3. Cenários propostos quanto a previsão de demanda de ferroligas

\begin{tabular}{|c|c|c|c|c|c|}
\hline \multirow{2}{*}{ Ferroligas } & \multicolumn{3}{|c|}{ Entradas } & \multirow{2}{*}{ RNA } & \multirow{2}{*}{ MER } \\
\hline & Descrição & Variáveis & Unidade & & \\
\hline \multirow[t]{7}{*}{ FeMnAC } & PVP & $X I=378100$ & $\mathrm{t}$ & $2348 t$ & $2370 \mathrm{t}$ \\
\hline & PMP & $X 2=391000$ & $\mathrm{t}$ & & \\
\hline & Consumo Específico & $X 3=0,0021215$ & $\mathrm{~kg} / \mathrm{t}$ & & \\
\hline & Previsão consumo & $\times 4=700$ & $\mathrm{t}$ & & \\
\hline & Lead time & $\times 5=90$ & dias & & \\
\hline & Estoque segurança & $\times 6=2100$ & $\mathrm{t}$ & & \\
\hline & Estoque inicial & $X 7=429,830$ & $\mathrm{t}$ & & \\
\hline \multirow[t]{7}{*}{ Al gotão } & PVP & $X I=500000$ & $\mathrm{t}$ & $405, I t$ & $402,9 t$ \\
\hline & PMP & $\times 2=450000$ & $\mathrm{t}$ & & \\
\hline & Consumo Específico & $X 3=0,0011893$ & $\mathrm{~kg} / \mathrm{t}$ & & \\
\hline & Previsão consumo & $\times 4=400$ & $\mathrm{t}$ & & \\
\hline & Lead time & $\times 5=10$ & dias & & \\
\hline & Estoque segurança & $X 6=133$ & $\mathrm{t}$ & & \\
\hline & Estoque inicial & $X 7=130$ & $\mathrm{t}$ & & \\
\hline \multirow[t]{7}{*}{$\mathrm{FeNb}$} & PVP & $X I=378100$ & $\mathrm{t}$ & $6,98 \mathrm{t}$ & $5,02 \mathrm{t}$ \\
\hline & PMP & $X 2=391000$ & $\mathrm{t}$ & & \\
\hline & Consumo Específico & $X 3=0,0000247$ & $\mathrm{~kg} / \mathrm{t}$ & & \\
\hline & Previsão consumo & $X 4=10$ & $\mathrm{t}$ & & \\
\hline & Lead time & $\times 5=5$ & dias & & \\
\hline & Estoque segurança & $\times 6=2$ & $\mathrm{t}$ & & \\
\hline & Estoque inicial & $\times 7=5$ & $\mathrm{t}$ & & \\
\hline
\end{tabular}

\section{CONCLUSÕES}

Para que se pudesse chegar ao bom desempenho da rede neural artificial, premissas importantes levantadas na literatura foram consideradas como a seleção das variáveis relacionadas a demanda, montagem da arquitetura da rede e treinamento da rede utilizando o algoritmo apropriado a minimização do erro de aprendizagem.

Após as recomendações, pode se observar que os resultados obtidos foram satisfatórios levando em consideração que as variáveis de entrada selecionadas neste trabalho foram importantes para o desenvolvimento da rede.

Identificou-se que o modelo RNA foi mais apropriado do que o MER para o cálculo de previsão de demanda, visto que o erro médio da RNA foi de $0,52 \%$ contra $2,65 \%$ do MER, onde os resultados do modelo RNA se mostraram mais próximos aos valores realizados nos históricos de dados, levando-se à conclusão que previsões de demandas e compras futuras baseados em cenários planejados também seriam acurados.
Para os cenários propostos de cada matéria prima pode se observar que a equipe de planejamento da CSN terá uma assertividade maior quanto à previsão de demanda utilizando o método rede neural artificial.

Com isso, conclui-se que se aplicado o modelo de RNA nos cálculos de previsão de demanda de ferroligas na CSN pode se obter um ganho de R\$ 2 milhões aproximadamente no valor de estoque imobilizado da empresa, consequentemente elevando o giro de estoque de I 3 para I5, melhoria no atendimento aos clientes internos, minimização do risco da falta de material e possível ruptura no processo produtivo.

\section{Agradecimentos}

As equipes de planejamento, vendas e aciaria da CSN e Universidade Federal Fluminense (UFF) pela disponibilização do software.

\section{REFERÊNCIAS}

I Ballou R. Gerenciamento da cadeia de suprimentos/logística empresarial. 5. ed. Porto Alegre: Bookman; 2006.

2 Setyawati BR, Creese RC, Sahirman S. Neural network for cost estimation (part 2). Morgantown. AACE International Transactions. 2003; I4:I-10.

3 Fish KE, Blodgett JG. A visual method for determining variable importance in an artificial neural net. Journal of Targeting, Measurement and Analysis for Marketing. 2003; I I (3):244-254. 
4 Silva IN, Spati DH, Flauzino RA. 20 I0. Redes neurais artificiais: para engenharia e ciências aplicadas. São Paulo: Artliber; 2010.

5 Castro JA, Feiteira JFS, França AB. Utilização de Redes neurais artificiais e modelo CFD como estratégia para tomada de decisões no processo do alto-forno. In: Escola de Eng. Industrial Metalúrgica de Volta Redonda UFF. Anais do $39^{\circ}$ Seminário de Redução de Minério de Ferro e Matérias-Primas; 2009 Novembro 22-26; Ouro Preto, Brasil. Volta Redonda: UFF.

6 Simões, M. G., Shaw, I. S. Controle e modelagem fuzzy. São Paulo: Blucher, FAPESF; 2007.

Recebido em: 12 Maio 2017

Aceito em: 28 Set., 2018 